Bangladesh J. Pl. Breed. Genet., 25(2): 09-14, 2012

\title{
GENETIC DIVERSITY IN RESTORER LINES OF HYBRID RICE (Oryza sativa L.)
}

\author{
M. J. Hasan, Umma Kulsum, M. H. Rahman, M. Nur-E-Elahi ${ }^{1}$ \\ and A. K. M. Shamsuddin ${ }^{2}$ \\ Hybrid Rice Division \\ Bangladesh Rice Research Institute \\ Gazipur 1701, Bangladesh
}

\begin{abstract}
An experiment was conducted with 30 restorer lines to identify most diverse lines in respect of morphological traits for developing heterotic rice hybrids. Thirty restorer lines were classified into four distinct clusters based on mean values of different morphological traits and days to maturity. Again these restorer lines were partitioned into very early, early, medium and late maturing groups. Only one line in very early maturing group had tall plant stature with maximum thousand grain weight but less in yield potential. Early maturing group contained 8 lines from different clusters having short plant stature with short flag leaf and moderate yielding ability. Medium maturing group included 13 lines characterized by medium plant stature with high tillering, excellent spikelet fertility, high grains per panicle and very good yielding ability. Late maturing group contained 8 lines featured by tall plant stature with excellent yield and yield contributing characters. Late maturing restorers BR827R, BR168R and BR736R had maximum genetic distance from centroid indicating extent of heterosis and very high yielding ability. Combining ability and heterosis study with short duration CMS lines may be fruitful for the development of desired hybrid.
\end{abstract}

Key words: Rice (Oryza sativa L.); restorer lines; morphological traits; combining ability; CMS; hybrid rice.

\section{INTRODUCTION}

Today, rice has attained special position of providing 50 to $80 \%$ of the daily calorie intake of the Asian population and more than three billion of world populations (Khush, 2005; Amirjani, 2011). Population is increasing and it would be over 4.6 billion by 2050 (Honarnejad et al., 2000). Rice production should be increased by $50 \%$ to feed the increased population (Ashikari et al., 2005; Srividya et al., 2010). Yield of improved rice varieties in favorable conditions has reached a plateau or even subsequently declined in many countries including Bangladesh. It is recommended that a large number of high yielding varieties are required to meet specific socio-economic and agricultural needs. Bangladesh is the fourth largest producer and consumer of rice in the world with an annual production ranging from 32 to 35 million tons. About $75 \%$ of the total cropped land is covered by rice and more than $60 \%$ of the labor force is engaged in rice production. Rice alone contributes around $10 \%$ to the GDP. Thus the single crop rice has a multiple effect on our daily life and economy (Iftekharuddaula et al., 2011). To meet

\footnotetext{
${ }^{1}$ Bangladesh Rice Research Institute, Gazipur 1701, Bangladesh; ${ }^{2}$ Department of Genetics and Plant Breeding, Bangladesh Agricultural University, Mymensingh 2202, Bangladesh
} 
the challenge of producing more rice under these challenges, we need new technologies like hybrid rice that gives $15-30 \%$ yield advantage over inbred rice. Moreover, hybrid rice has also shown better performance under adverse conditions like drought and saline conditions. Increasing demand for rice especially in developing countries hybrid rice is considered as a viable alternative technology for breaking the present yield ceiling of modern varieties. So far one hundred and eight (108) hybrid rice varieties of various private companies and public organization were released by the National Seed Board (SCA, 2012). Majority of these hybrids are imported from China and most of them are low in amylose content which is one of the determinants of cooking quality of rice. In Boro seasons 2011-2012, total sold rice hybrid was 8800 MT of which $45 \%$ were imported from China and the rest 55\% from local production (Huda and Ali, 2012). If we develop or improve parental lines of hybrid rice based on diversity we can find most diverse parents that will help developing heterotic hybrid combinations. Such a way we can save lots of foreign currency and make a remarkable impact on our national economy. This study will help in selection of more distantly related restorer lines for using in crossing program and ultimately help to develop high yielding hybrid rice varieties in local conditions. So, the knowledge of diversity among parental lines is very much important. With this view, this study was undertaken to evaluate the restorer lines based on cluster analysis and days to maturity.

\section{MATERIALS AND METHODS}

The experiment was conducted at the experimental field of Bangladesh Rice Research Institute (BRRI), Gazipur during T. Aman season 2007. Thirty restorer lines were evaluated to identify most diverse lines in respect of morphological traits for developing heterotic rice hybrids based on clustering and days to maturity. Twenty one days old single seedling was transplanted with a spacing of $20 \mathrm{~cm} \times 15 \mathrm{~cm}$ in RCB design with three replications. The unit plot size was $1.8 \mathrm{~m} \times 1.0 \mathrm{~m}$. Adequate soil fertility was ensured by applying Urea-TSP-MP-Gypsum-ZnSO $@$ 150:100:70:60:10 kg/ha, respectively. Total TSP, MP, Gypsum and $\mathrm{ZnSO}_{4}$ were applied during final land preparation. The urea was applied in three installments, at 15 days after transplanting (DAT), 30 DAT and 45 DAT. Necessary intercultural operations was carried out during cropping period for proper growth and development of the plants. Ten sample plants were randomly selected from each plot excluding the border plants and the following data were recorded: Plant height $(\mathrm{cm})$, number of effective tillers per plant, days to $50 \%$ flowering, flag leaf length $(\mathrm{cm})$, panicle weight $(\mathrm{g})$, spikelet fertility $(\%)$, grains per panicle, days to maturity, 1000 grain weight $(\mathrm{g})$ and grain yield per plot $(\mathrm{kg})$. List of restorer lines along with country of origin is given in Table 1.

\section{Euclidean distance}

Euclidean or straight-line measure of distance (ED) is the most commonly use statistic for estimating genetic distance between individuals (genotypes or populations) by morphological data. Euclidean distance between two individuals $i$ and $j$, having observations on morphological characters $(p)$ denoted by $x_{1}, x_{2}, \ldots, x_{p}$ and $y_{1}, y_{2}, \ldots, y_{p}$ for $i$ and $j$, respectively, can be calculated by the following formula: $d(i, j)=\left[\left(x_{1}-y_{1}\right)^{2}-\right.$ $\left.\left(x_{2}-y_{2}\right)^{2}+\ldots\left(x_{p}-y_{p}\right)^{2}\right]^{1 / 2}$

The centroid is the middle of a cluster. It is a vector containing one number for each variable, where each number is the mean of a variable for the observations in that cluster. The centroid is used as a measure of cluster location. For a given cluster, the average distance from the centroid is the average of the distances between observations 
and the cluster centroid. The maximum distance from the centroid is the maximum of these distances. ED was measured using Minitab statistical software, Minitab Inc. USA. Dendrogram showing the dissimilarity in 30 restorer lines for days to maturity is shown in figure 1.

Table 1. List of restorer lines used in this experiment

\begin{tabular}{|c|c|c|c|c|c|}
\hline $\begin{array}{l}\text { SL. } \\
\text { No. }\end{array}$ & Restorer lines & $\begin{array}{l}\text { Country of } \\
\text { origin }\end{array}$ & $\begin{array}{l}\text { SL. } \\
\text { No. }\end{array}$ & Restorer lines & $\begin{array}{l}\text { Country of } \\
\text { origin }\end{array}$ \\
\hline 01 & BR827R & Bangladesh & 16 & IR73004-107-3-3-2R & Philippines \\
\hline 02 & BR168R & Bangladesh & 17 & IR73004-7-3-3-3R & Philippines \\
\hline 03 & BR736R & Bangladesh & 18 & IR64R & Philippines \\
\hline 04 & BR6723-1-1-2R & Bangladesh & 19 & IR46R & Philippines \\
\hline 05 & BR6839-41-5-1R & Bangladesh & 20 & IR71137-328-2-3-3-3-2R & Philippines \\
\hline 06 & BR7013-62-1-1R & Bangladesh & 21 & IR73885-1-4-1-4-4-3-6R & Philippines \\
\hline 07 & BR7011-37-1-2R & Bangladesh & 22 & IR69716-37-1-1-5-IR & Philippines \\
\hline 08 & M.H.63R & China & 23 & AjayaR & India \\
\hline 09 & M.H.77R & China & 24 & IR73013-95-1-3-2R & Philippines \\
\hline 10 & Gui99R & China & 25 & IR44675R & Philippines \\
\hline 11 & Wan3R & China & 26 & IR32809-26-3-3R & Philippines \\
\hline 12 & IR40750R & Philippines & 27 & IR72887-38-1-3-2R & Philippines \\
\hline 13 & IR7320-44-2-3-IR & Philippines & 28 & IR72906-24-1-3-IR & Philippines \\
\hline 14 & PSBRC82R & Philippines & 29 & IR69702-3-2-3R & Philippines \\
\hline 15 & IR68011-15-1-12-3R & Philippines & 30 & IR69701-41-3-IR & Philippines \\
\hline
\end{tabular}

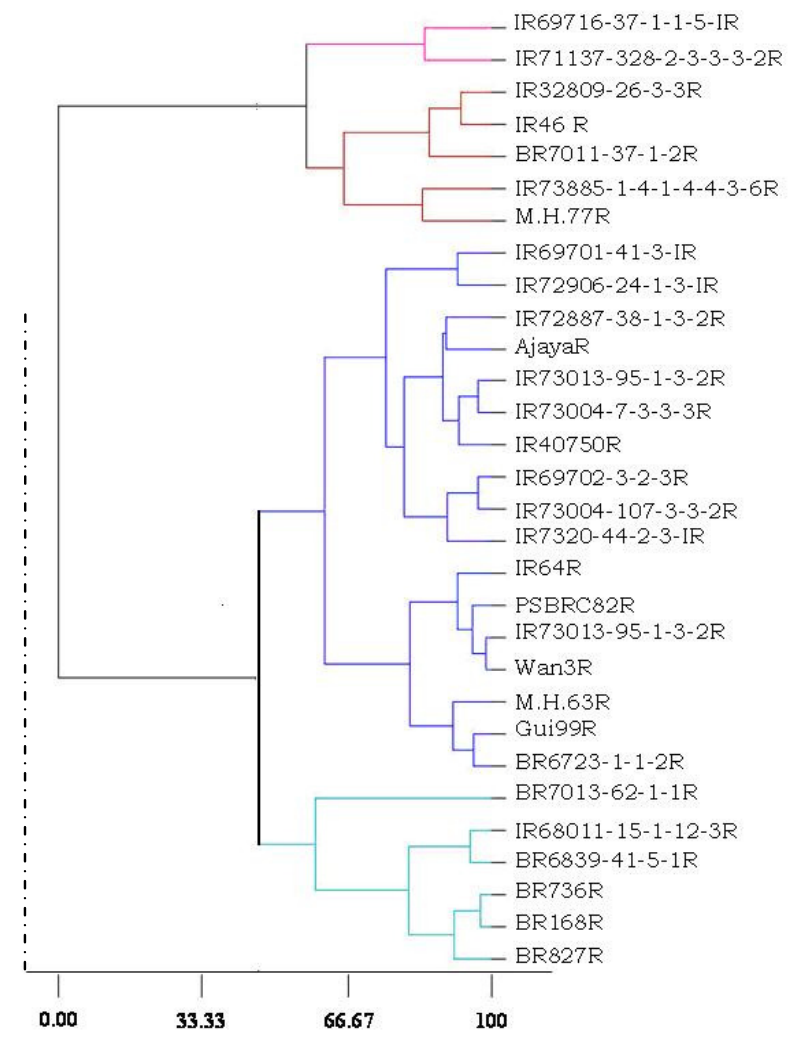

Figure 1: Dendrogram showing the dissimilarity in 30 restorer lines for days to maturity 


\section{RESULTS AND DISCUSSION}

Thirty restorer lines were grouped into 4 clusters on the basis of yield and yield contributing characters. Again these restorer lines were partitioned into very early (96 to104 days), early (105 to 112 days), medium (113 to 120 days) and late (121 to 134 days) maturing groups (Table 2). There was no consistency of grouping the lines on the basis of maturity and clustering them on the basis of yield and yield contributing characters. The very early maturing group belonged to only a single line. Early maturing group contained 8 lines from different clusters. Medium maturing group contained 13 lines and they were from cluster 1, 2 and 3. Late maturing group included 8 lines from the cluster 1,2 and 3.

Table 2. Grouping of 30 restorer lines of rice based on Euclidean Distance and maturity

\begin{tabular}{c|l|c|c}
\hline Group & \multicolumn{1}{c}{ Restorer lines } & Number of lines & Cluster ID \\
\hline Very early & IR69716-37-1-1-5-IR & 1 & 4 \\
& BR6723-1-1-2R, M.H.63R, Gui99R, Wan3R, IR64R & 5 & 2 \\
Early & M.H.77R, IR46R & 2 & 3 \\
& IR71137-328-2-3-3-3-2R & 1 & 4 \\
& BR6839-41-5-1R, BR7013-62-1-1R, IR68011-15-1-12-3R & 3 & 1 \\
\multirow{5}{*}{ Medium } & IR40750R, IR7320-44-2-3-IR, PSBRC82R, IR73004-7-3-3-3R & 8 & 2 \\
& AjayaR, IR73013-95-1-3-2R, IR44675R, IR72906-24-1-3-IR & 2 & 3 \\
& BR7011-37-1-2R, IR73885-1-4-1-4-4-3-6R & 3 & 1 \\
& BR827R, BR168R, BR736R & 4 & 2 \\
Late & IR73004-107-3-3-2R, IR72887-38-1-3-2R, IR69702-3-2-3R, & 4 & 3 \\
& IR69701-41-3-IR & 1 & \\
\hline
\end{tabular}

Mean values for yield and yield contributing characters within four maturing groups were presented in Table 3 . Very early maturing group contained one restorer line (IR69716-37-1-1-5-IR) that fell into cluster 4. It had tall plant stature with maximum thousand grain weight but least in average yield potential. Early maturing group contained 8 lines having short plant stature with short flag leaf and moderate yielding ability.

Table 3. Mean values for yield and yield contributing characters within four maturing groups

\begin{tabular}{l|c|c|c|c|c|c|c|c|c|c}
\hline \multicolumn{1}{c}{ Group } & $\begin{array}{c}\mathrm{PH} \\
(\mathrm{cm})\end{array}$ & ET & $\begin{array}{c}\text { DFF } \\
(\text { days })\end{array}$ & $\begin{array}{c}\text { FLL } \\
(\mathrm{cm})\end{array}$ & $\begin{array}{c}\text { PW } \\
(\mathrm{g})\end{array}$ & $\begin{array}{c}\text { SF } \\
(\%)\end{array}$ & $\begin{array}{c}\text { grains/ } \\
\text { panicle }\end{array}$ & $\begin{array}{c}\text { DM } \\
(\text { days })\end{array}$ & $\begin{array}{c}1000 \\
\mathrm{GW}(\mathrm{g})\end{array}$ & $\begin{array}{c}\mathrm{Gy} / \\
\mathrm{plot} \\
(\mathrm{g})\end{array}$ \\
\hline Very early & 128.3 & 5.00 & 73.00 & 37.70 & 2.45 & 74.71 & 125.00 & 98.00 & 25.98 & 422.4 \\
Early & 106.4 & 6.63 & 84.00 & 33.81 & 2.19 & 78.52 & 166.29 & 110.63 & 25.85 & 672.1 \\
Medium & 112.5 & 7.08 & 91.92 & 36.32 & 2.40 & 81.43 & 176.08 & 118.69 & 23.85 & 755.9 \\
Late & 118.0 & 7.40 & 100.5 & 39.30 & 2.90 & 83.50 & 181.80 & 130.00 & 22.20 & 917.2 \\
\hline
\end{tabular}

PT= Plant height; ET= No. of effective tillers; DFF= Days to 50\% flowering; FLL= Flag leaf length; PW= Panicle weight; $\mathrm{SF} \%=$ Spikelet fertility; DM= Days to maturity; 1000GW=1000 grain weight; Gy/plot= Grain yield per plot

Medium maturing group included 13 lines characterized by medium plant stature with high tillering, excellent spikelet fertility, high number of grains/panicle and very good yielding ability. Late maturing group contained 8 lines featured by tall plant stature with excellent yield and yield contributing characters. Morphological trait analysis of hybrid rice is a useful tool in studying the difference in ecological type, which is closely related to heterosis (Wang et al., 2006). Distance between cluster centroid among 30 restorer lines ranged from 2.95to 5.78 (Table 4). The lowest distance from centroid was 
found between cluster 1 and cluster 2 and the highest was found between cluster 1 and cluster 4 followed by cluster 1 and 3 .

Maximum distance of cluster 1 from centroid was 3.42. Cluster 1 contained 6 restorer lines and they were BR6839-41-5-1R, BR7013-62-1-1R, IR68011-15-1-12-3R, BR827R, BR168R and BR736R. First three restorer lines of this cluster belonged to medium maturing group and rest three from late maturing group. Cluster 2 contained 17 restorer lines and its maximum distance from centroid was 3.26 with average distance from centroid was 2.36 (Table 5). Late maturing restorers BR827R, BR168R and BR736R had maximum distance from centroid indicating presence of variability from other restorer lines fallen in different clusters. Within the same cluster having genetic similarities but genotypes fallen in different clusters having genetic dissimilarities (Everitt et al., 2001). Shamsuddin (1985) reported genetic divergence between the parents had a positive relationship with heterosis and SCA effects of the hybrids in spring wheat.

Table 4. Distances between Cluster Centroid in 30 restorer lines of rice

\begin{tabular}{lcc|c|c}
\hline & Cluster 1 & Cluster 2 & Cluster 3 & Cluster 4 \\
\hline Cluster1 & $\mathbf{0 . 0 0}$ & & & \\
Cluster2 & 2.95 & $\mathbf{0 . 0 0}$ & & \\
Cluster3 & 5.29 & 2.98 & $\mathbf{0 . 0 0}$ & \\
Cluster4 & 5.78 & 4.38 & 3.53 & $\mathbf{0 . 0 0}$ \\
\hline
\end{tabular}

Table 5. Different statistics of Euclidean distance and cluster analysis of 30 restorer lines

\begin{tabular}{c|c|c|c|c}
\hline Cluster & $\begin{array}{c}\text { No. of restorer } \\
\text { lines }\end{array}$ & $\begin{array}{c}\text { Within cluster } \\
\text { sum of squares }\end{array}$ & $\begin{array}{c}\text { Average distance } \\
\text { from centroid }\end{array}$ & $\begin{array}{c}\text { Maximum distance } \\
\text { from centroid }\end{array}$ \\
\hline Cluster1 & 6 & 33.47 & 2.28 & 3.42 \\
Cluster2 & 17 & 99.21 & 2.36 & 3.26 \\
Cluster3 & 5 & 29.40 & 2.37 & 3.02 \\
Cluster4 & 2 & 6.05 & 1.74 & 1.74 \\
\hline
\end{tabular}

Among the 17 restorer lines under cluster 2, five fell into early maturing group, eight into medium maturing group and rest four in late maturing group. Cluster 3 contained 5 restorer lines and its maximum distance from centroid was 3.02 with average distance from centroid was 2.37 . Out of 5 restorer lines in cluster 3, two fell into early maturing group, two in medium maturing and the rest one in late maturing group. Cluster 4 contained 2 restorer lines and its maximum and average distance from centroid was 1.74. Out of two restorer lines under cluster 4 , one fell in very early maturing group and other in early maturing group. Out of 30 restorer lines cluster 1 included restorer lines from medium and late maturing groups but late maturing group had the highest yield potentiality. So, combining ability and heterosis study between late maturing high yield potential restorer lines with medium duration stable CMS lines may yield desired type hybrid combination that perform better under local condition.

\section{ACKNOWLEDGEMENTS}

This work was supported by Ministry of Agriculture, Government of the People's Republic of Bangladesh through a project "Research and Development of Hybrid Rice in Bangladesh". 


\section{REFERENCES}

Amirjani, M. R. 2011. Effect of salinity stress on growth, sugar content, pigments and enzyme activity of rice. International Journal of Botany. 7(1): 73-81.

Ashikari, M., H. Sakakibara, S. Lin, T. Yamamoto and T. Takashi 2005. Cytokinin oxidase regulates rice grain production. Science. 309: 741-745.

Everitt, B. S., S. Landau and M. Leese 2001. Cluster analysis, Fourth edition, Arnold.

Honarnejad, R., S. Abdollahi, M. S. Mohammad-Salehi and H. Dorosti 2000. Consideration of adaptability and stability of grain yield of progressive rice (Oryza sativa L.) lines. Res. Agric. Sci., 1: 1-9.

Huda, N and Shahjahan Ali 2012. Hybrid rice seed technology in Bangladesh. Issues and Considerations. Seminar presented at BARC, Farm gate, Dhaka on September 18,2012

Ifterkharuddaula, K. M., M. R. Islam, T. L. Aditya, J. K. Biswas and M. K. Bashar 2011. Development of climate change resilient rice varieties: current status and potential. Souvenir, SAARC seed congress \& fair 2011, held at Bangabandhu International Conference Centre during 10-12 April, 2011, Dhaka, Bangladesh.

Khush, G. S. 2005. What it will take to feed 5.0 billion rice consumers in 2030. Plant Molecular Biology. 59: 1-6.

Seed Certification Agency. 2012. List of released hybrid rice varieties from 1997 to2011.

Shamsuddin, A. K. M. 1985: Genetic diversity in relation to heterosis and combining ability in spring wheat. Theor Appl Genet. 70: 306-308.

Srividya, A., L. R. Vemireddy, A. S. Hariprasad, M. Jayaprada and S. Sridhar 2010. Identification and mapping of landrace derived QTL associated with yield and its components in rice under different nitrogen levels and environments. International Journal of Plant Breeding and Genetics. 4: 210-227.

Wang, S. J., Z. M. Lu and J. M. Wan 2006. Genetic diversity among parents of hybrid rice based on cluster analysis of morphological traits and simple sequence repeat markers. Rice Science. 13(3): 155-160. 